\title{
A Medium-Voltage Matrix Converter Topology for Wind Power Conversion with Medium Frequency Transformers
}

\author{
Chunyang $\mathrm{Gu}^{*}$, Harish S. Krishnamoorthy ${ }^{* *}$, Prasad N. Enjeti ${ }^{* *}$, Zedong Zheng ${ }^{*}$, and Yongdong $\mathrm{Li}^{\dagger}$ \\ ${ }^{*}$ Department of Electrical Engineering, Tsinghua University, Beijing, China \\ ** Department of Electrical and Computer Engineering, Texas A\&M University, College Station, TX, USA
}

\begin{abstract}
A new type of topology with medium-frequency-transformer (MFT) isolation for medium voltage wind power generation systems is proposed in this paper. This type of converter is a high density power conversion system, with high performance features suitable for next generation wind power systems in either on-shore or off-shore applications. The proposed topology employs single-phase cascaded multi-level AC-AC converters on the grid side and three phase matrix converters on the generator side, which are interfaced by medium frequency transformers. This avoids DC-Link electrolytic capacitors and/or resonant L-C components in the power flow path thereby improving the power density and system reliability. Several configurations are given to fit different applications. The modulation and control strategy has been detailed. As two important part of the whole system, a novel single phase AC-AC converter topology with its reliable six-step switching technique and a novel symmetrical 11-segment modulation strategy for two stage matrix converter (TSMC) is proposed at the special situation of medium frequency chopping. The validity of the proposed concept has been verified by simulation results and experiment waveforms from a scaled down laboratory prototype.
\end{abstract}

Key words: Matrix converters, Medium Frequency Transformer (MFT), Medium Voltage (MV), Multi-level converter, Wind power conversion

\section{INTRODUCTION}

Permanent Magnet (PM) Wind Turbine Generators (WTGs) are becoming popular for use in high power energy conversion because of their high power density and flexibility in operation. The most common power conversion scheme for PM WTGs is the direct drive topology. The interface to the utility grid is challenging, especially in the Medium Voltage (MV) level [1], with a large step-up line frequency transformer and DC-link electrolytic capacitors, as shown in Fig. 1.

Matrix Converter (MC) is an "all Silicon solution" with semiconductor switches without the need for any storage capacitors. A few advantages of the matrix converter approach

Manuscript received May 31, 2014; accepted Oct. 6, 2014

Recommended for publication by Associate Editor Seung-Ki Sul.

†Corresponding Author: liyd@tsinghua.edu.cn

Tel: +86-10-6278-5481, Fax: +86-10-6277-2450, Tsinghua University

*Department of Electrical Engineering, Tsinghua University, China

Department of Electrical \& Computer Engineering, Texas A\&M

University, USA when implemented to wind power conversion systenms include, a continuously adjustable output frequency, high quality current waveforms, a bidirectional power flow, smaller size and compact design due to the absence of electrolytic capacitors [2], [3], unity power factor input and output currents, and freedom for the switching pattern control due to the existence of bidirectional switches [4], [5]. One limitation of matrix converters is that the magnitude of the output voltage is equal to $86 \%$ of the input voltage. However, this is not seen as a major problem if the transformer winding ratio can be suitably adjusted to match the voltage gain.

In [6], [7], the matrix converter concept was extended to the MV level for a high-power drive that has bidirectional power flow capability and very low harmonics in input current and output voltage. The MV matrix converter is implemented by connecting power cells in series which consist of three-phase input and single-phase output matrix converters. Such a topology still requires a step-up line frequency transformer for MV grid integration, as shown in Fig. 2.

Some of the converters used to interface variable speed 


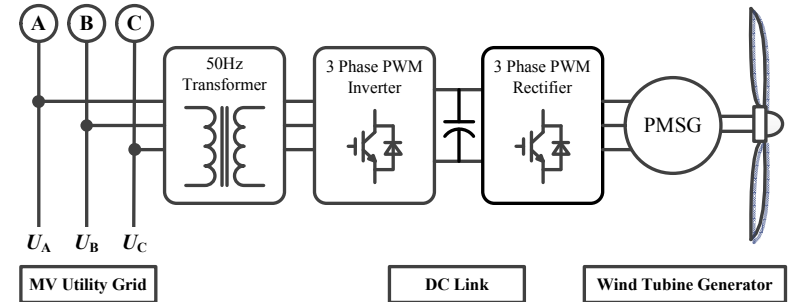

Fig. 1. Conventional power conversion scheme for PM WTG.

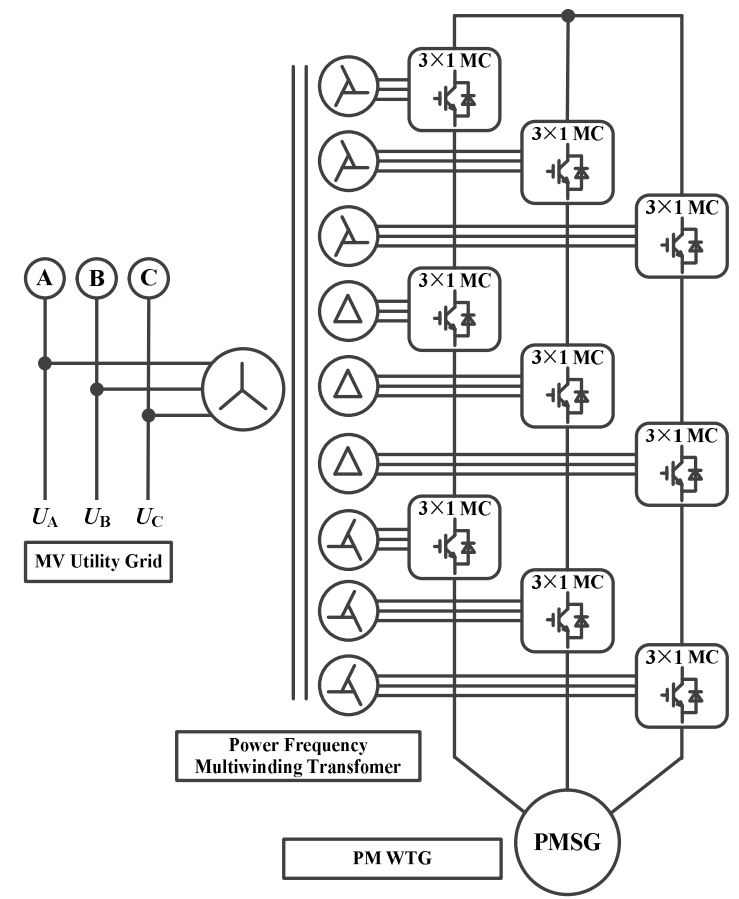

Fig. 2. Conventional medium voltage (MV) cascaded matrix converter powered WTG.

WTGs with the utility grid employ high frequency transformers (HFTs) [8]-[13]. High efficiency for a wide transferred power range is an important factor in variable speed wind turbine systems [11]. Other interface converters with HFT have some drawbacks. The isolated buck type DC/DC converter using an uncontrolled rectifier interface converter in [12] has insufficient voltage regulation capability and high currents in the primary side of the HFT at the rated wind speed may reduce the efficiency of the converter. A complex dual LCL DC/AC converter with an HFT is used in [13]. The soft switching nature of this converter requires a stable DC voltage that has to be maintained for the entire input voltage range, which reduces the controlled rectifier efficiency at low generator speeds.

The authors of [14] proposed a new configuration for a main traction converter with an MFT using matrix converters. In [15], [16], a modular H-bridge cascaded converter with a multi-winding HFT was proposed for applications in medium or high voltage fields. In [17], a MV WTG - energy storage grid interface converter topology with MFT isolation was introduced in which PWM rectifiers and PWM inverters are used for the WTG driving. These converter topologies can reduce the weight and volume of the system. However, one of the disadvantages of these topologies is the fact that the large DC-Link capacitors in the power flow path decrease the power density and reliability [18].

In this paper, a new MC based topology with MFT isolation for high power wind turbine systems is investigated, as shown in Fig. 3. The system involves MFTs with series stacked AC/AC converters on the MV utility side and 3-phase matrix converter on the WTG side. Therefore, no DC link electrolytic capacitors are used in the system. The major advantages of the proposed system are as follows:

- The MF link transformer provides galvanic isolation as well as proper voltage matching between the utility and the WTG. It also contributes to reduced size/weight while maintaining a high transfer efficiency.

- The input side converters are series connected. They employ lower voltage IGBTs/ MOSFETs and voltage sharing is guaranteed by the transformer coupling and input capacitors.

- The AC-AC converters and matrix converter are modulated to make a utility power factor and a WTG power factor near unity, with low harmonics in the currents.

- The proposed approach does not employ DC-Link capacitors and/or series resonant L-C components in the power flow path. This increases both the power density and reliability.

Different topology configurations for a matrix converter with MFT isolation are given in Section II. The modulation and control strategies is illustrated in Section III. This includes a novel single phase AC-AC converter topology and switching technique as well as a novel 11-segment modulation strategy for three phase matrix converters. Simulation and experimental results are presented in Section IV and Section V. Conclusions are given in Section VI.

\section{Proposed Matrix CONVERTER TOPOlOGY WITH MFT ISOLATION}

The topology of the proposed MV matrix converter with MFT isolation is shown in Fig. 3. It can be divided into several parts: an LC filter connected to the utility grid, cascaded single phase AC-AC converters, multi winding MFTs for isolation, three phase matrix converters connected to the WTG and so on.

The input LC filter is the interface between utility grid and the wind power system. It is used to smooth the grid current. Since cascaded multi-level AC-AC converters switch at a medium frequency, the weight and volume of the input filter could be reduced by the operation of a current control method. The utility side has several series connected AC-AC converters. The WTG side has multiple 3-phase AC-AC 


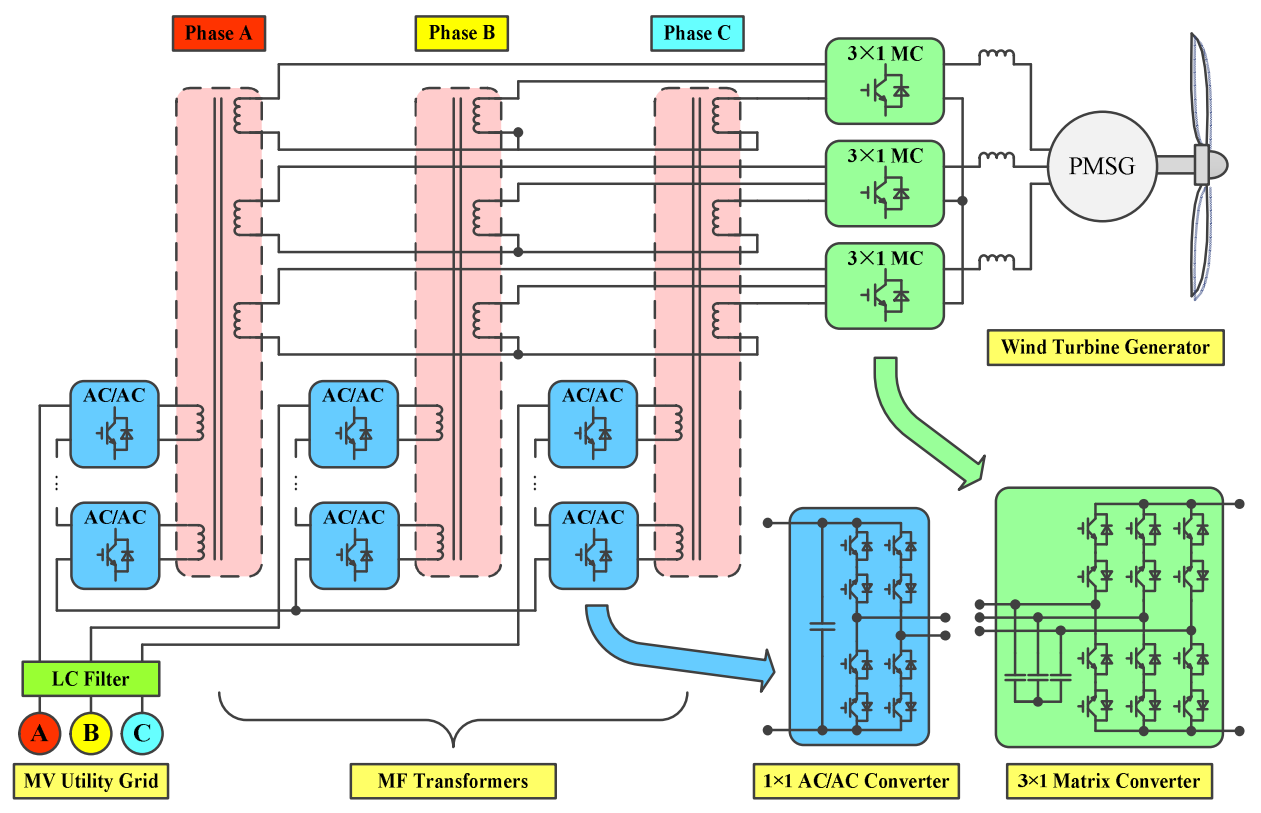

Fig. 3. Proposed MV matrix converter with MFT isolation for wind power generation.

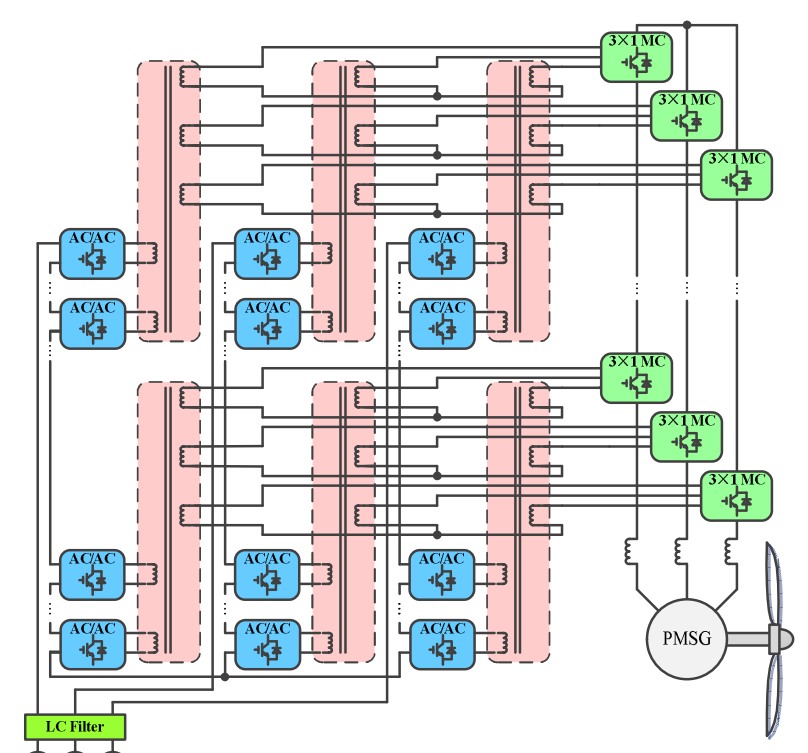

(A) B)

Fig. 4. Proposed MV matrix converter (modular multi-level matrix converter configuration).

converters (or matrix converters). The MFT operating frequency is decided based on the power requirements of the application.

The alterable structures of both the $1 \times 1$ AC-AC converters and the three phase matrix converter can be used for different applications.

To fit a higher voltage level utility grid or to achieve better performance for the WTG power conversion, a modular multilevel configuration is proposed, as shown in Fig. 4.

To further decrease the number of switching devices and to decrease the weight and volume of the system, different

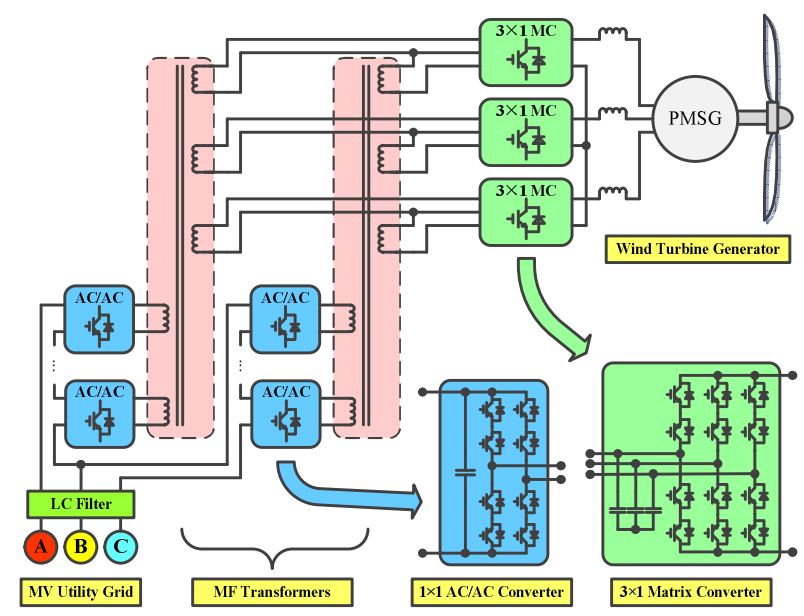

Fig. 5. Proposed MV matrix converter (open delta configuration).

configurations can be used. In Fig. 5, an open delta configuration is proposed to reduce one third of the single phase AC-AC converters and transformers.

Fig. 6 shows a delta configuration with a $3 \times 3$ matrix converter. Cascaded multi-level AC-AC converters connect to the grid by the delta connection scheme. The number of switching devices is reduced by using one $3 \times 3$ matrix converter instead of three $3 \times 1$ matrix converters as the main converter on the PMSG side.

Table I shows a brief comparison of the four different structures for the proposed novel converter shown in Fig. 3 to Fig. 6. Since a $3 \times 1$ matrix converter is easy to cascade and is the basic part of the modular multi-level matrix converter structure, the universality of the $3 \times 1$ matrix converter structure is high. For a $3 \times 3$ matrix converter structure, the 
TABLE I

CONTRAST OF Four DiFFERENT CONFIGURATIONS

\begin{tabular}{ccccc}
\hline Items & $\begin{array}{c}3 \times 1 \\
\text { matrix } \\
\text { converter } \\
\text { structure }\end{array}$ & $\begin{array}{c}\text { Modular } \\
\text { multi-level } \\
\text { matrix } \\
\text { converter } \\
\text { structure }\end{array}$ & $\begin{array}{c}\text { Open } \\
\text { delta } \\
\text { structure }\end{array}$ & $\begin{array}{c}3 \times 3 \\
\text { matrix } \\
\text { converter } \\
\text { structure }\end{array}$ \\
\hline Universality & high & low & low & high \\
$\begin{array}{c}\text { Output } \\
\text { Performance } \\
\text { Number of } \\
\text { devices }\end{array}$ & medium & high & low & medium \\
\hline
\end{tabular}

universality is high because it is commonly used for lower power applications. The modular multi-level matrix converter structure has the highest output performance because of its multilevel output voltage. The open delta structure has the lowest output performance because it only works well in three phase balanced conditions.

\section{MFT DESIGN FOR THE NEW CONVERTER}

Medium frequency transformers are the core part of the whole system. The critical problems of MFT design are frequency, power and efficiency. In [10] and [19], the MFT of $1.5 \mathrm{MVA} / 5 \mathrm{kHz}$ and $10 \mathrm{kHz} / 350 \mathrm{kVA}$ with a high insulation voltage were designed for high speed railway applications by Alstom and ABB. For a $1 \mathrm{kHz}$ applications, a silicon steel core can be used due to its good its magnetic field intensity. When the working frequency increases, it is necessary to use an amorphous or nano-crystalline core to reduce the hysteresis losses.

In the proposed converter, a high insulation voltage (larger than $10 \mathrm{kV}$ ) MFT is needed. To decrease the switching frequency of the secondary side matrix converters and to decrease both the hysteresis losses and the cost of the system, a $1 \mathrm{kHz}$ MFT with a silicon steel core is used. The magnetic field intensity is set to $1.2-1.5 \mathrm{~T}$.

The non-ideal effect of a medium frequency transformer is mainly from the leakage inductance. The analysis in the next part (Fig. 14) shows that when the leakage inductance is less than $0.1 \mathrm{mH}$, the proposed converter works in a safe condition.

\section{MOdUlation STRATEGIES AND CONTROL ALGORITHM}

\section{A. Cascaded Single Phase AC-AC Converter}

Traditionally, a cascaded single phase AC-AC converter is made up of multiple levels of full bridge modules with bidirectional switches, as shown in Fig. 7(a). Therefore, four bidirectional switches with medium frequency switching are

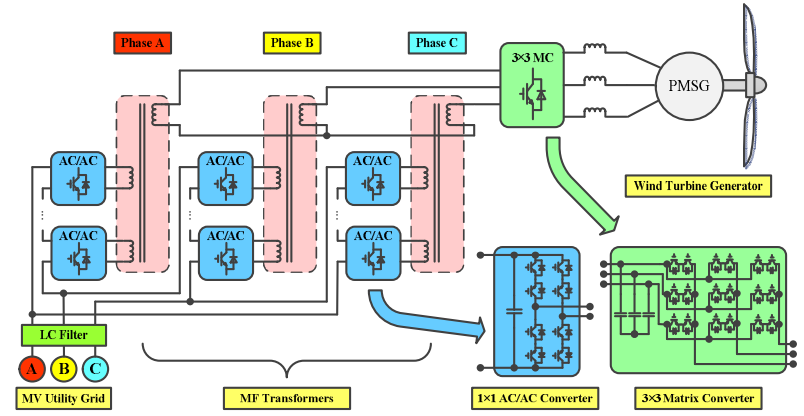

Fig. 6. Proposed MV matrix converter (delta configuration with $3 \times 3$ matrix converter).

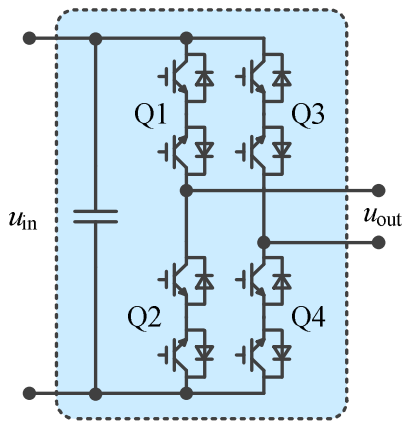

(a) Traditional single phase AC-AC converter with bidirectional switches.

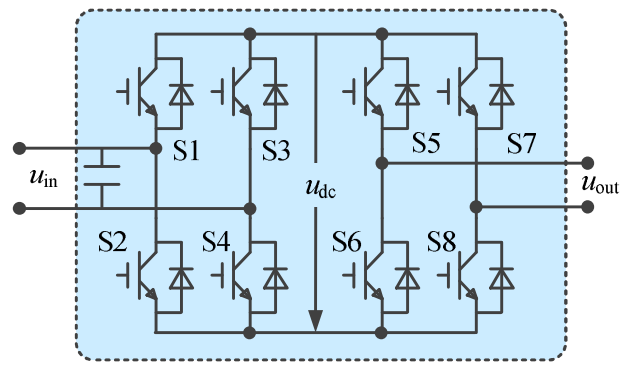

(b) A novel single phase AC-AC converter with $\mathrm{H}$-bridge modules especially for medium frequency chopping.

Fig. 7. Single phase AC-AC converter topologies.

needed

The modulation strategy of this traditional AC-AC converter is very simple. The gate signals of Q1 and Q4 are a medium frequency square wave, and the gate signals of Q2 and Q3 are the reverse of Q1 and Q4.

Although the modulation of a traditional AC-AC converter is simple, its switching sequence is not. Four step switching is needed since it is still a direct matrix converter.

Another shortcoming of a traditional AC-AC converter is that all eight of the switches are working in the medium-frequency hard switching mode. Therefore, the switching losses cannot be ignored.

In view of these disadvantages, a new single phase AC-AC converter is proposed in this paper, as shown in Fig. 7(b). The novel converter module is made up of two simple back to 
TABLE II

Vectors For VSI of Novel Single Phase AC-AC CONVERTer

\begin{tabular}{ccccc}
\hline S5 & S6 & S7 & S8 & Vector \\
\hline 0 & 1 & 0 & 1 & V0 \\
1 & 0 & 0 & 1 & V1 \\
0 & 1 & 1 & 0 & V2 \\
1 & 0 & 1 & 0 & V3 \\
\hline
\end{tabular}

back H-bridges without any DC-link capacitors. The performance of this converter is not good enough as a single phase matrix converter. However, it is particularly suitable for the proposed MV matrix converter topology in this paper.

The major advantages of the novel single phase AC-AC converter are:

- The single phase AC-AC converter with back to back H-bridge modules performs well as a grid frequency voltage to a medium frequency voltage chopper.

- Since no four step switching is needed, the switching control is uncomplicated.

- The switching losses are lower than the traditional converter because the switching frequency of the switches in the grid-connected H-bridge is $50 \mathrm{~Hz}$ or $60 \mathrm{~Hz}$ with Zero Current Switching (ZCS), and the switching frequency of the four switches in the MFT-connected H-bridge is a medium frequency.

- Since there is a DC bus in the converter, the clamping circuit is more simple than that of traditional converters.

The natural switched-on condition of the S1 and S4 anti-parallel diode is $u_{i n}>U_{\mathrm{f}}$, and the switched-on condition of the S2 and S3 diode is $u_{i n}<-U_{\mathrm{f}}$, where $U_{\mathrm{f}}$ is the forward voltage of the diode. As a result, S2 and S3 must be switched off when $u_{i n}>U_{\mathrm{f}}$, and S1 and S4 must be switched off when $u_{i n}<-U_{\mathrm{f}}$.

The novel single phase AC-AC converter is an indirect matrix converter configuration. The switching of the rectifier (grid-connected H-bridge) should been accomplished at the moment of the zero vector output of the inverter (MFT-connected H-bridge), as shown in Table II.

On the basis of the previous analysis, a six-step switching technique is proposed as shown in Fig. 8 (a).

At the time of $t_{0}, u_{i n}>U_{\mathrm{d}}, \mathrm{S} 1=\mathrm{S} 4=1, \mathrm{~S} 2=\mathrm{S} 3=0, \mathrm{~S} 5=\mathrm{S} 8=1$, and $\mathrm{S} 6=\mathrm{S} 7=0$, where $U_{\mathrm{d}} \geq U_{\mathrm{f}}$.

At the time of $t_{1}, u_{i n} \approx U_{\mathrm{d}}, \mathrm{S} 8$ turns off; At the time of $t_{2}$, $\mathrm{S} 7$ turns on, the vector of inverter is $\mathrm{V} 3$ (a zero vector). At the time of $t_{3}, \mathrm{~S} 1$ and $\mathrm{S} 4$ turns off.

At the time of $t_{4}, u_{i n} \approx-U_{\mathrm{d}}, \mathrm{S} 2$ and S3 turn on.

At the time of $t_{5}$, S5 turns off.

At the time of $t_{6}$, S6 turns on.

After the time of $t_{6}, u_{i n}<-U_{\mathrm{d}}, \mathrm{S} 1=\mathrm{S} 4=0, \mathrm{~S} 2=\mathrm{S} 3=1$, $\mathrm{S} 5=\mathrm{S} 8=0$, and $\mathrm{S} 6=\mathrm{S} 7=1$. At this time, the switching process is completed.

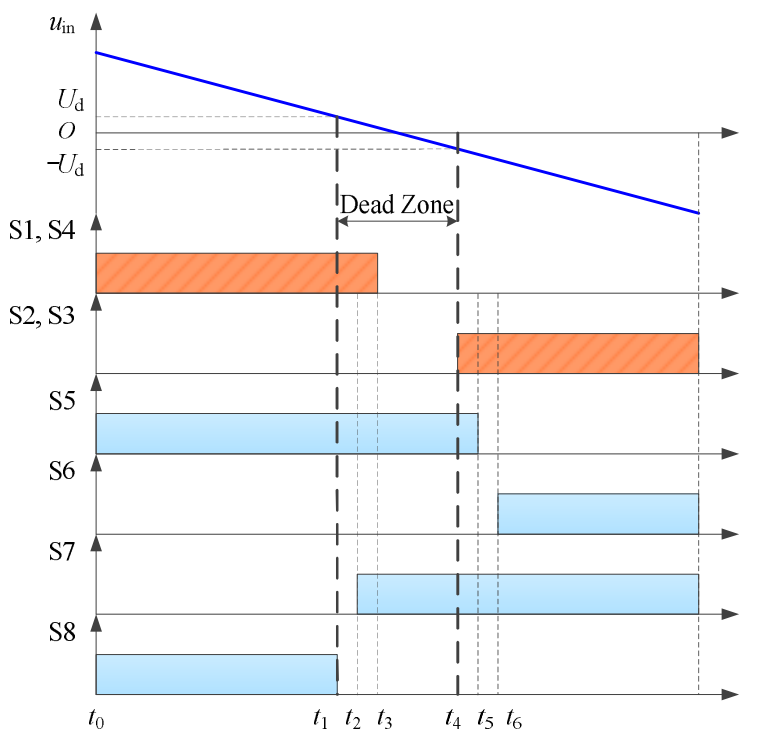

(a) Common situation.

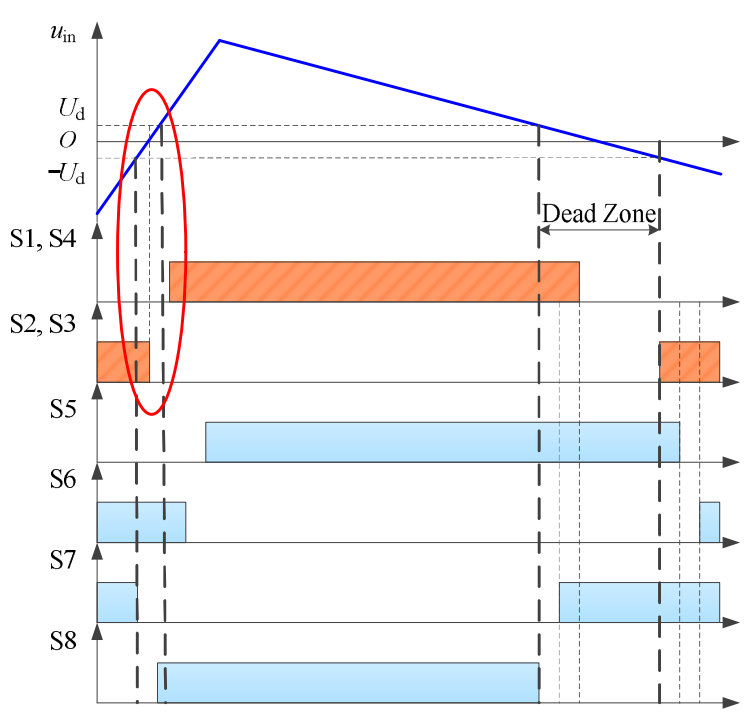

(b) Sudden glitches near zero crossing point.

Fig. 8. Six-step switching technique for the novel single phase AC-AC converter.

The time ranges $t_{1}$ to $t_{2}, t_{2}$ to $t_{3}, t_{4}$ to $t_{5}$, and $t_{5}$ to $t_{6}$ are the dead times of the switching devices.

As shown in Fig. 8 (b), when the half time of the dead zone is less than two times the switching dead time (e.g. sudden glitches near the zero crossing point), S2 and S3 will turn off when the voltage crosses the zero point. S1 and S4 will turn on after the dead time (a delay) when there is a departure from the dead zone. Therefore, the ZCS of S2 and S3 is missing. However, the system is still running in a safe condition.

Fig. 9 shows the whole switching modulation strategy of the novel single phase AC-AC converter. $\operatorname{Sign}\left(u_{\text {in }}\right)$ is the sign function of $u_{\text {in }}$. The rise and fall edges of $\operatorname{Sign}\left(u_{\text {in }}\right)$ are uncertain because of sampling errors. "Flag" is a logical mark 


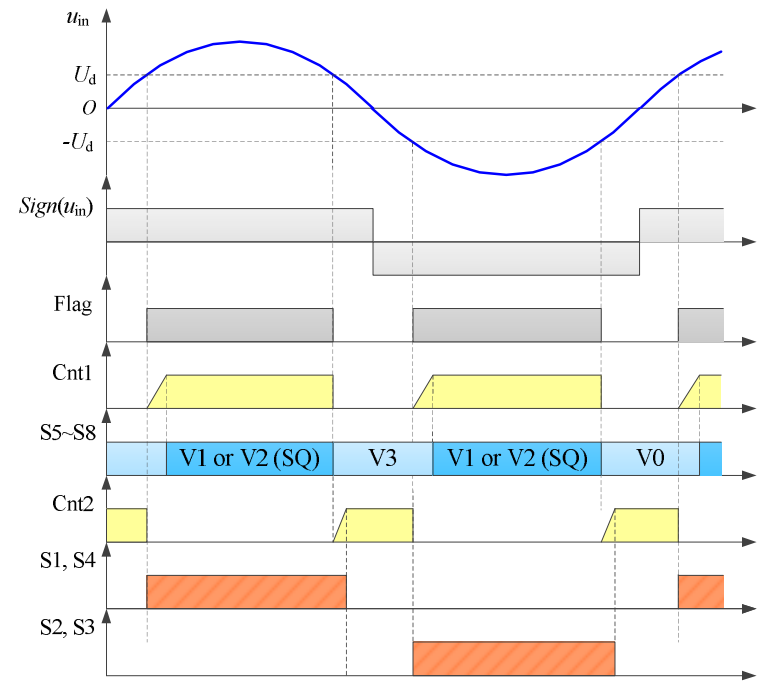

Fig. 9. Whole switching modulation strategy of the novel single phase AC-AC converter.
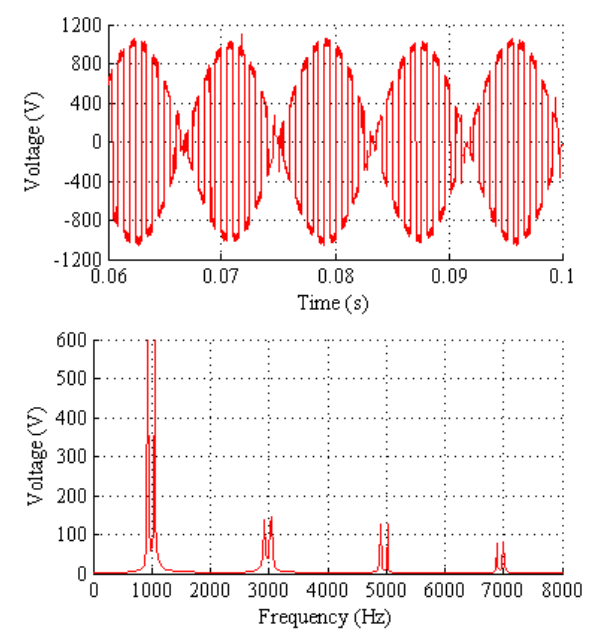

Fig. 10. Output voltage waveforms and FFT analysis of single phase AC-AC converter.

when $u_{i n}>U_{\mathrm{d}}$ and $u_{i n}<-U_{\mathrm{d}}$. For practical applications, a Schmitt toggle circuit is used for better tolerance to sampling circuit errors. Otherwise the identification circuits of the diode voltages are needed for accurate application. "Cnt1" and "Cnt2" are the dead time counters between the rectifier gate signals and the inverter gate signals.

For a $4160 \mathrm{~V}$ medium voltage application, at least four AC-AC converters need to be cascaded with $1700 \mathrm{~V}$ IGBTs. When the single phase AC-AC converter is modulated with a square wave of medium frequency, the output voltage is a product of the input voltage and the square wave switching function, as shown in Fig. 10.

When the utility grid voltage frequency is $f_{\mathrm{s}}=60 \mathrm{~Hz}$, and the single phase AC-AC converter is modulated with a square wave of medium frequency, say $f_{\mathrm{sq}}=1 \mathrm{kHz}$, the major frequency components of the output voltage are around medium frequency $\left(f_{\mathrm{sq}} \pm f_{\mathrm{s}}\right)$. It is significant that $f_{\mathrm{sq}}$ is limited by the transformer core material.

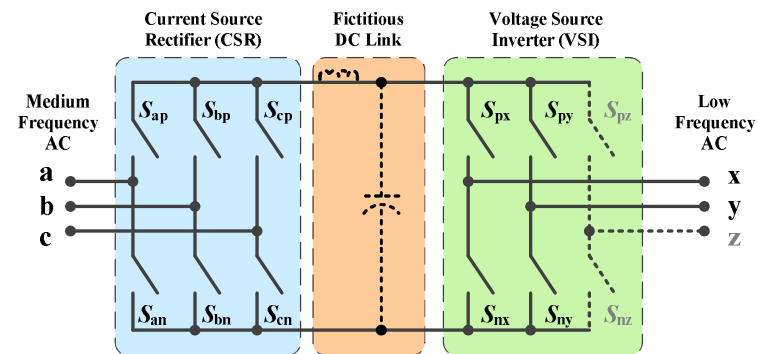

Fig. 11. Matrix converter with the combination of CSR and VSI modulations.

\section{B. Matrix Converter Operation}

The matrix converter of the secondary side of the transformers converts a 3-phase medium AC to a 3-phase or single phase low frequency AC output. A MC operation can be illustrated by separating it into a current source rectifier (CSR), a fictitious DC link and a voltage source inverter (VSI), as shown in Fig. 11. The VSI could be either three-phase (for $3 \times 3 \mathrm{MC}$ ) or single-phase (for $3 \times 1 \mathrm{MC}$ ).

The switching function of a matrix converter is a product of the rectifier switching function and the inverter switching function.

$$
\begin{aligned}
T_{S} & =T_{i n v} T_{r e c} \\
& =\left[\begin{array}{lll}
S_{a x} & S_{b x} & S_{c x} \\
S_{a y} & S_{b y} & S_{c y} \\
S_{a y} & S_{b y} & S_{c y}
\end{array}\right] \\
& =\left[\begin{array}{lll}
S_{a p} S_{p x}+S_{a n} S_{n x} & S_{b p} S_{p x}+S_{b n} S_{n x} & S_{c p} S_{p x}+S_{c n} S_{n x} \\
S_{a p} S_{p y}+S_{a n} S_{n y} & S_{b p} S_{p y}+S_{b n} S_{n y} & S_{c p} S_{p y}+S_{c n} S_{n y} \\
S_{a p} S_{p z}+S_{a n} S_{n z} & S_{b p} S_{p z}+S_{b n} S_{n z} & S_{c p} S_{p z}+S_{c n} S_{n z}
\end{array}\right]
\end{aligned}
$$

Several PWM schemes can be employed. The choice of which scheme to use depends on the quality of the input current, the switch operating frequency, the switching losses, etc. To get better performance from a matrix converter, SVPWM might be used for both the CSR and VSI modulations. For the transformer input voltage (chopped sinusoidal voltage), the sign function (MF square wave) must be considered while using SVPWM:

$$
U_{\text {in }}=\left[\begin{array}{l}
u_{\mathrm{a}} \\
u_{\mathrm{b}} \\
u_{\mathrm{c}}
\end{array}\right]=U_{m}\left[\begin{array}{c}
\sin \left(2 \pi f_{s} t\right) \cdot \operatorname{sign}\left[\sin \left(2 \pi f_{\mathrm{sq}} t\right)\right] \\
\sin \left(2 \pi f_{s} t-\frac{2}{3} \pi\right) \cdot \operatorname{sign}\left[\sin \left(2 \pi f_{\mathrm{sq}} t\right)\right] \\
\sin \left(2 \pi f_{s} t+\frac{2}{3} \pi\right) \cdot \operatorname{sign}\left[\sin \left(2 \pi f_{\mathrm{sq}} t\right)\right]
\end{array}\right]
$$

Since a square wave $\mathrm{S}_{\mathrm{SQ}}=\operatorname{sign}\left[\sin \left(2 \pi f_{\mathrm{sq}} t\right)\right]$ is a predictable waveform created by digital signal controller units, grid voltages $U_{\text {in }}{ }^{\prime}$ can be used instead of medium frequency voltages $U_{i n}$.

$$
U_{i n}^{\prime}=\left[\begin{array}{c}
u_{\mathrm{a}}^{\prime} \\
u_{\mathrm{b}}{ }^{\prime} \\
u_{\mathrm{c}}^{\prime}
\end{array}\right]=\left[\begin{array}{l}
u_{\mathrm{ga}} \\
u_{\mathrm{gb}} \\
u_{\mathrm{gc}}
\end{array}\right]=U_{m}\left[\begin{array}{c}
\sin \left(2 \pi f_{s} t\right) \\
\sin \left(2 \pi f_{s} t-\frac{2}{3} \pi\right) \\
\sin \left(2 \pi f_{s} t+\frac{2}{3} \pi\right)
\end{array}\right]
$$




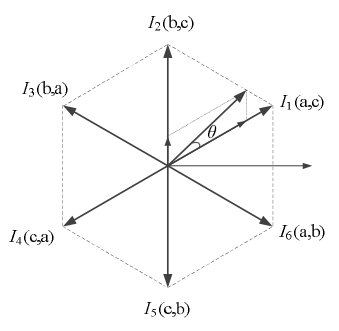

(a) CSR vectors.

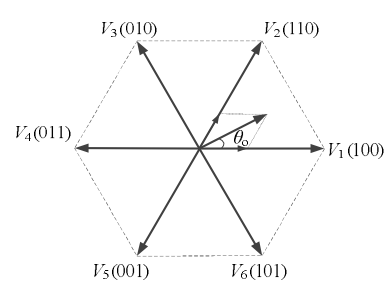

(b) VSI vectors.
Fig. 12. SVPWM vector for a TSMC.

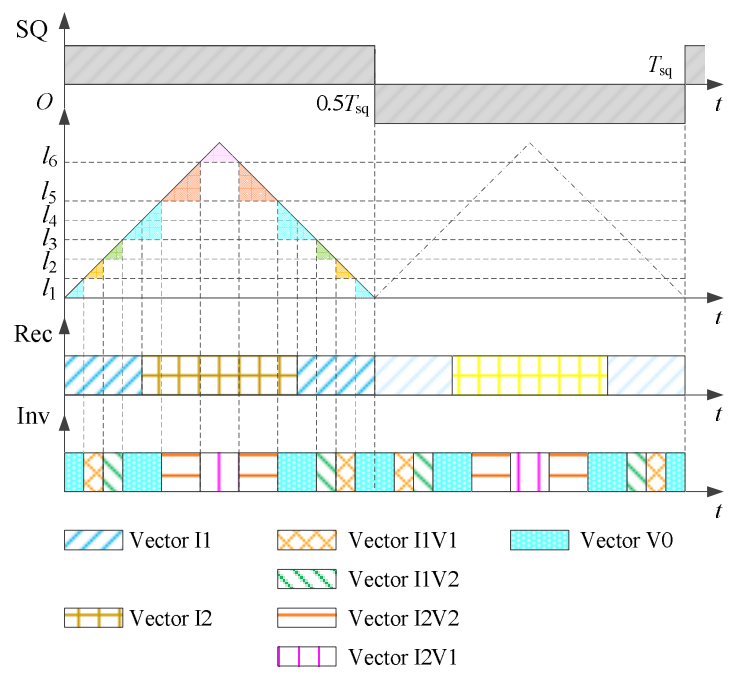

Fig. 13. A novel symmetrical 11-segment modulation strategy.

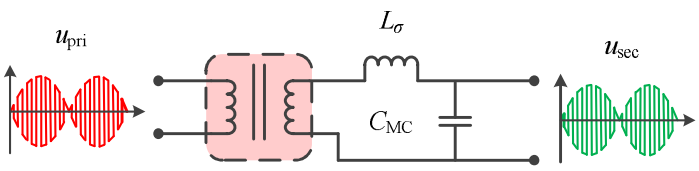

Fig. 14. Low-pass filter effect of secondary side voltage of MFT.

The matrix converter of a 3-phase medium frequency AC to a low frequency AC output can be modulated in the same way as the matrix converter of a 3-phase gird frequency AC to a low frequency AC output. For a two stage matrix converter (TSMC), the SVPWM vector is shown in Fig. 12.

To add the influence of a medium frequency square wave to traditional matrix converter modulation, a novel symmetrical 11-segment modulation strategy is proposed, as shown in Fig. 13. The minimum rectifier modulation frequency $f_{\text {rec }}$ is $2 f_{\mathrm{sq}}$, and the inverter minimum modulation frequency $f_{\text {inv }}$ is $4 f_{\mathrm{sq}}$. In a period of the rectifier modulation frequency, both rectifier and inverter modulation is symmetrical. Therefore, the switching harmonics will be reduced when compared with the other methods.

Fig. 13 shows the rectifier switches when the inverter is in the vector $\mathrm{V} 0$ condition. As a result, the rectifier is in the ZCS modulation status which will decrease the losses as well as the switching overvoltage. The detailed modulation information is in Equation (4). The zero vector time is equally divided into three parts in one rectifier switching period.

$$
\left\{\begin{array}{l}
l_{1}=\frac{1}{3} D_{0} \\
l_{2}=\frac{1}{3} D_{0}+D_{\mathrm{I1}} D_{\mathrm{V} 1} \\
l_{3}=\frac{1}{3} D_{0}+D_{11} D_{\mathrm{V} 1}+D_{\mathrm{I1}} D_{\mathrm{V} 2} \\
l_{4}=\frac{2}{3} D_{0}+D_{\mathrm{II}} D_{\mathrm{V} 1}+D_{\mathrm{I1}} D_{\mathrm{V} 2} \\
l_{5}=D_{0}+D_{11} D_{\mathrm{v} 1}+D_{11} D_{\mathrm{V} 2} \\
l_{6}=D_{0}+D_{11} D_{\mathrm{V} 1}+D_{11} D_{\mathrm{V} 2}+D_{12} D_{\mathrm{V} 2}
\end{array}\right.
$$

As shown in Fig. 13 and Equation (4), to implement this 11-segment modulation strategy in a CPLD or an FPGA, six comparison lines are created $\left(l_{1} \sim l_{6}\right)$ as a modulating wave. In addition, a triangle wave is created as a carrier wave. In the time range between 0 and $l_{1}, l_{3}$ and $l_{5}$ are set to be $\frac{1}{3} D_{0}$. As a result, the vector 0 is equally separated into three parts. When the minimum value of $D_{0}$ is larger than three times the switching dead time, the reliability of the TSMC modulation is guaranteed.

Since in one switching period, the modulation is symmetrical, the output voltage waveform quality is better than the other asymmetric modulation strategies (e.g. 7-segment asymmetric modulation).

The major advantages of the novel symmetrical 11-segment modulation strategy for the TSMC are described as follows:

- When compared with the traditional 7-segment asymmetric modulation strategy and the 13-segment symmetrical strategy, the switching losses are lower because the switching frequency of the rectifier is half that of the traditional strategies.

- When compared with the traditional 7-segment asymmetric modulation strategy, the switching harmonics are lower.

- When compared with the traditional 7-segment asymmetric modulation strategy and the 13-segment symmetrical strategy, the modulation reliability is higher because the zero vector time period is equally divided into three parts. The minimum length of the zero vectors is limited by the maximum modulation ratio.

As shown in Fig. 14, the secondary circuit of the medium frequency transformer is a low-pass filter because the leakage inductance is not neglected.

When the leakage inductance $L_{\sigma}=0.1 \mathrm{mH}$ and the matrix converter input capacitance $C_{\mathrm{MC}}=1 \mathrm{nF}$, the time constant of the low pass filter is:

$$
\tau=2 \pi \sqrt{L_{\sigma} C_{\mathrm{MC}}}=1.986 \mu \mathrm{s}
$$




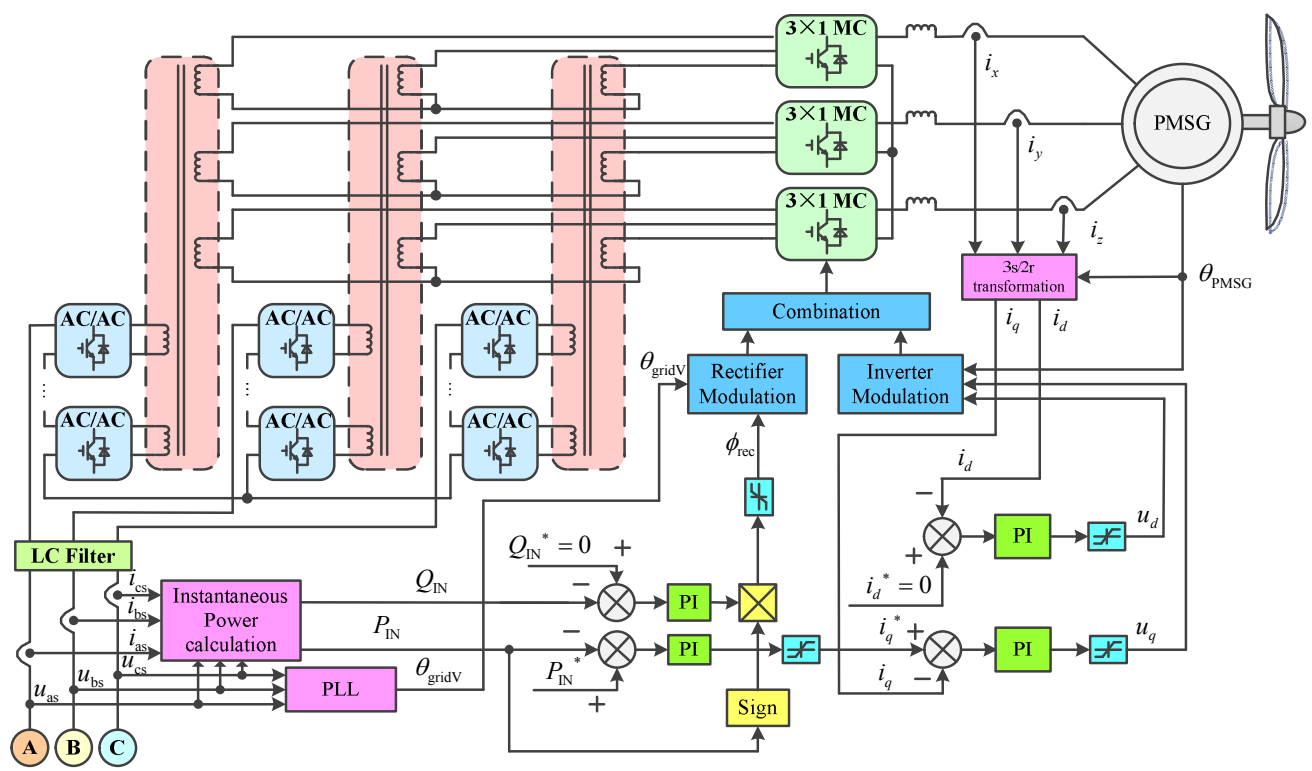

Fig. 15. Control algorithm of the MV MFT isolated matrix converter.

When rectifier switching frequency $f_{\text {rec }}=4 \mathrm{kHz}$ and the maximum modulation ratio of the inverter $M=0.8$, the minimum time of zero vectors is:

$$
\begin{aligned}
\left.\frac{1}{3} t_{\mathrm{v} 0}\right|_{\min }= & \frac{1}{3} \times \frac{1}{4 \mathrm{kHz}} \times(1-0.8)=16.7 \mu \mathrm{s} \\
\tau & \ll \frac{1}{3} t_{\mathrm{v} 0}
\end{aligned}
$$

From equation (7), the input voltage of the three phase matrix converter is good. The output voltage of the TSMC inverter can be a combination of an accurate duplicate of the three phase grid voltage.

\section{Control Strategy}

Fig. 15 shows the detailed control strategy for the proposed system. It mainly consists of two current loops and two power loops. The input reactive power loop to control $Q_{\mathrm{IN}}$ is to realize the unity power factor. The active power loop to control $P_{\mathrm{IN}}$ depends on the upper level power management instructions. The output of the active power loop is the reference of the $\mathrm{q}$ axis current as an inner loop. Another current loop is to regulate the $\mathrm{d}$ axis current to control the magnetic linkage of the PMSG. The inner PI controller can be replaced with a hysteresis controller, which yields a similar performance.

The power factor of the utility grid along with the output voltage and current can be well controlled. MPPT control and other upper level control strategies can be easily added to the basic control strategy.

\section{Simulation Results}

The proposed wind power generation topology (shown in Fig. 3) was simulated using PSIM software, for a power rating of $300 \mathrm{~kW}$ with a $2.45 \mathrm{kV}$ RMS medium voltage utility

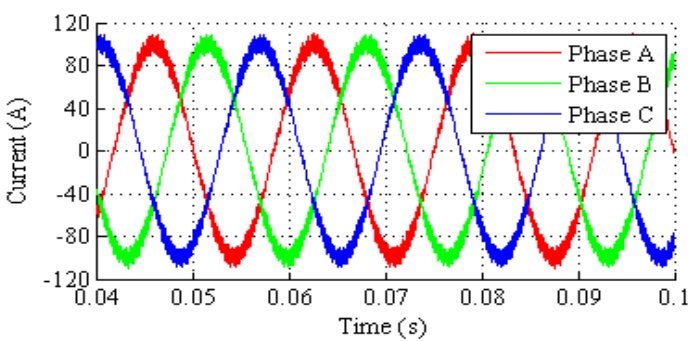

Fig. 16. Input current waveforms.

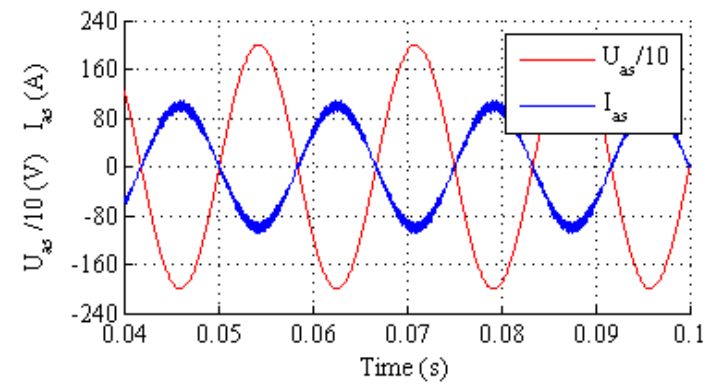

Fig. 17. Unity input power factor.

input. The configuration is a star-connected $3 \times 1$ matrix converter.

Fig. 16 shows the utility input phase currents $\left(i_{\mathrm{ga}}, i_{\mathrm{gb}}\right.$ and $i_{\mathrm{gc}}$ ). The transformer frequency (square wave frequency) is 1 $\mathrm{kHz}$, and the switching frequency of the secondary matrix converter (rectifier frequency) is $6 \mathrm{kHz}$.

Fig. 17 shows a phase shift comparison of the input voltage $u_{\text {ga }}$ and the input current $i_{\text {ga }}$. A unity power factor is realized via a close loop PI regulator. The input current waveforms are very good.

Fig. 18 shows the output phase voltage and current $\left(u_{x}\right.$, 


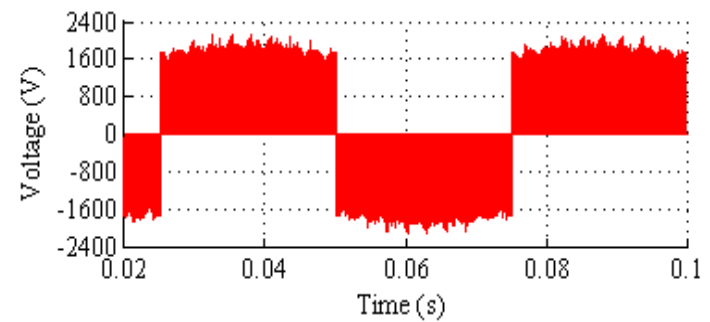

(a) Phase $x$ voltage.

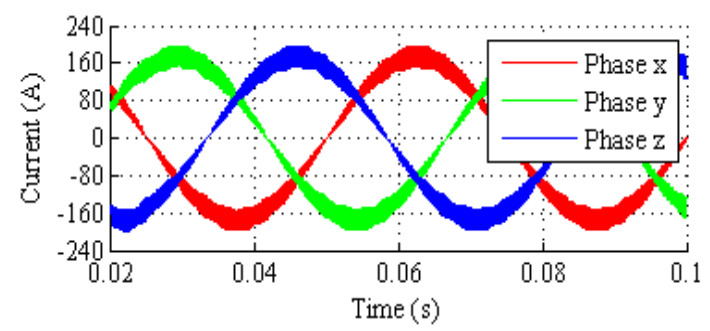

(b) Output current.

Fig. 18. Output voltage and current.

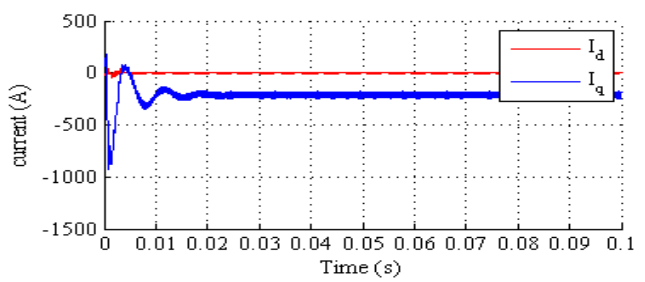

(a) The d-q axis current of WTG.

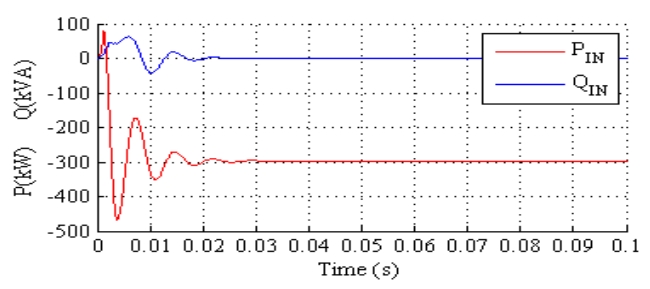

(b) Active and reactive power of the grid side.

Fig. 19. Power control results of the whole system.

$i_{x}, i_{y}$ and $i_{z}$ ) at the WTG side. The output frequency of the wind power generator is kept at $20 \mathrm{~Hz}$.

Fig. 19(a) shows the d-q current of the generator. It can be seen that the control target of $I_{\mathrm{d}}=0$ and $I_{\mathrm{q}}$ (negative constant value) is achieved. Furthermore, it can be seen from Fig. 19(b) that the input active and reactive powers of the utility grid are controlled appropriately.

\section{EXPERIMENTAL VERIFICATIONS}

A 6.6kVA experimental prototype was designed with three single-phase $1 \mathrm{kHz}$ MFTs. The AC-AC converter was built and operated at $1 \mathrm{kHz}$. To simplify the structure of the experimental platform, a TSMC is used as the secondary side converter, as shown in Fig. 20. Both the Input side and the output side of the system are separately connected to the utility grid.

To reduce the system volume, IGBT IKW40N120H3s of

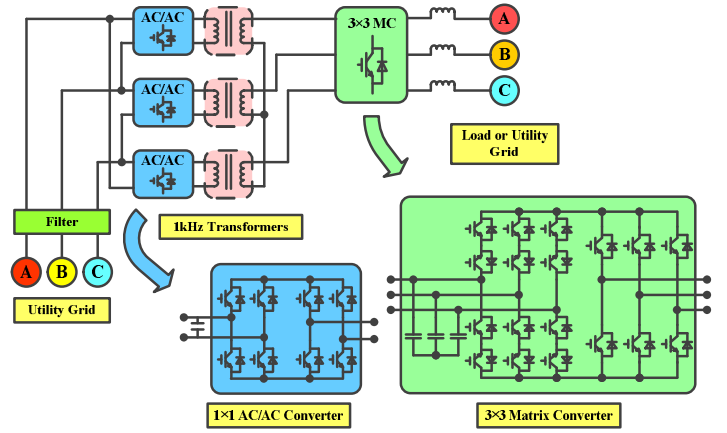

Fig. 20. Structure of the experimental platform.

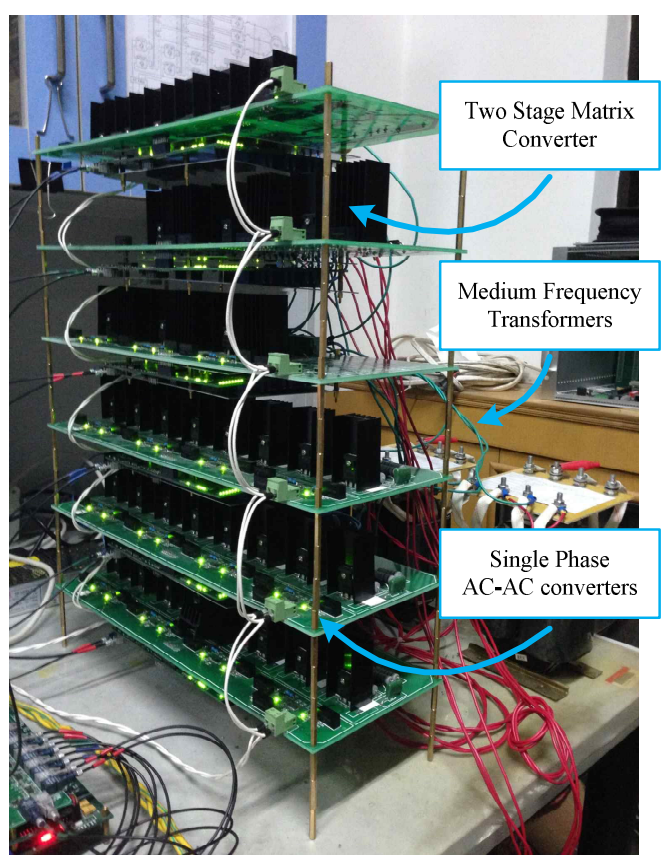

(a) Whole system.

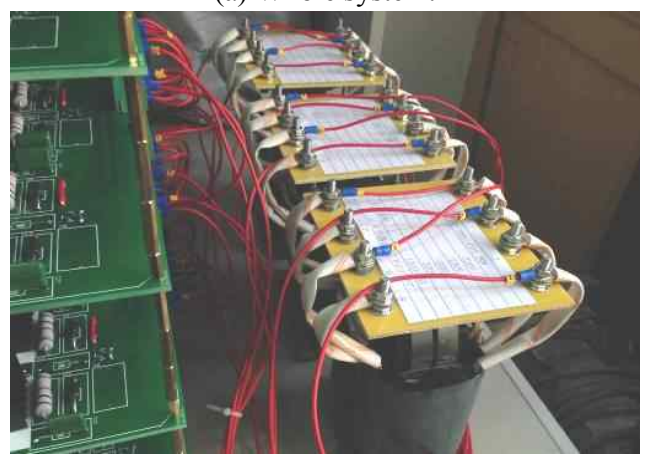

(b) Medium frequency transformers.

Fig. 21. Photograph of experimental platform.

$1200 \mathrm{~V}$ and $40 \mathrm{~A}$ are employed as switching devices. A TMS320F28335 DSP and a Cyclone II FPGA work together for system control and modulation.

Electrical circuit photos of the platform are shown in Fig. 21. There is only one module of the primary single phase $\mathrm{AC} / \mathrm{AC}$ converter in each phase. The switching frequency of the TSMC rectifier is $4 \mathrm{kHz}$, and the switching frequency of the TSMC inverter is $8 \mathrm{kHz}$. 
TABLE III

PARAMETERS AND CONDITIONS OF EXPERIMENTS

\begin{tabular}{c|c|c|c}
\hline $\begin{array}{c}\text { MFT } \\
\text { frequency }\end{array}$ & $1 \mathrm{kHz}$ & $\begin{array}{c}\text { Load } \\
\text { inductance }\end{array}$ & $5 \mathrm{mH}$ \\
\hline $\begin{array}{c}\text { MFT rating } \\
\text { voltage }\end{array}$ & $220 \mathrm{~V}$ & Load resistance & $40 \Omega$ \\
\hline $\begin{array}{c}\text { MFT rating } \\
\text { current }\end{array}$ & $10 \mathrm{~A}$ & $\begin{array}{c}\text { Input voltage } \\
\text { (Fig. 22) }\end{array}$ & $\begin{array}{c}36 \mathrm{~V} \\
\text { magnitude }\end{array}$ \\
\hline $\begin{array}{c}\text { Grid filter } \\
\text { capacitance }\end{array}$ & $20 \mathrm{mF}$ & $\begin{array}{c}\text { Input voltage } \\
\text { (Fig. 23) }\end{array}$ & $\begin{array}{c}150 \mathrm{~V} \\
\text { magnitude }\end{array}$ \\
\hline $\begin{array}{c}\text { Grid filter } \\
\text { inductance }\end{array}$ & $100 \mathrm{uH}$ & $\begin{array}{c}\text { Output voltage } \\
\text { (Fig. 26) }\end{array}$ & $\begin{array}{c}28 \mathrm{~V} \\
\text { magnitude }\end{array}$ \\
\hline $\begin{array}{c}\text { Grid } \\
\text { frequency }\end{array}$ & $50 \mathrm{~Hz}$ & $\begin{array}{c}\text { Grid voltage } \\
\text { (Fig. 29) }\end{array}$ & $\begin{array}{c}12 \mathrm{~V} \\
\text { magnitude }\end{array}$ \\
\hline
\end{tabular}

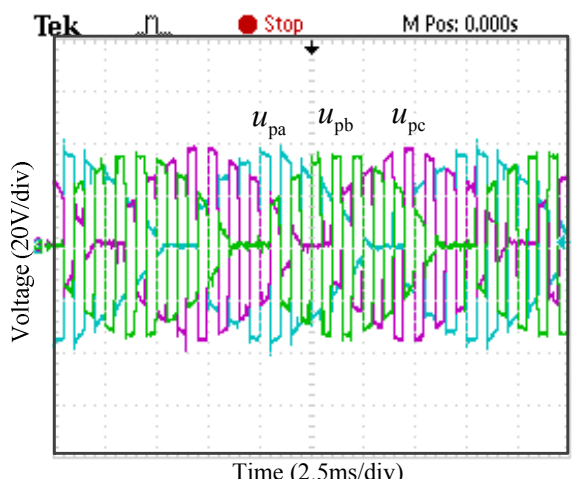

Fig. 22. Experimental waveforms of AC/AC converter output voltage.

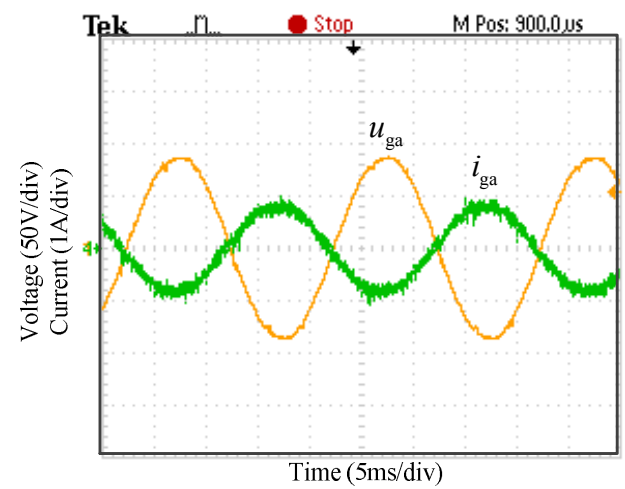

Fig. 23. Input voltage and current of Phase A.

The parameters of the experimental platform and the experiment conditions are shown in Table III.

The AC/AC converter output voltage waveforms are shown in Fig. 22.

Fig. 23 shows the input voltage and current of Phase A with a resistance-inductance load. It can be seen that the input current has a phase that is almost opposite that of the input voltage. It can also be seen that the power factor can be controlled very well.

Fig. 24 shows a comparison of the primary transformer

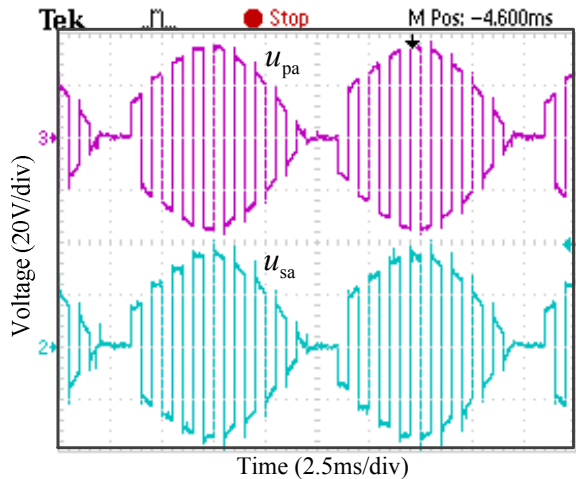

Fig. 24. Comparison of primary transformer voltage and secondary transformer voltage.

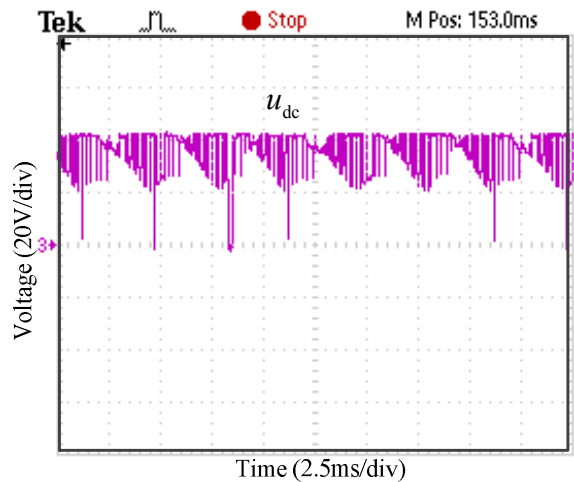

Fig. 25. DC bus voltage of three phase TSMC.

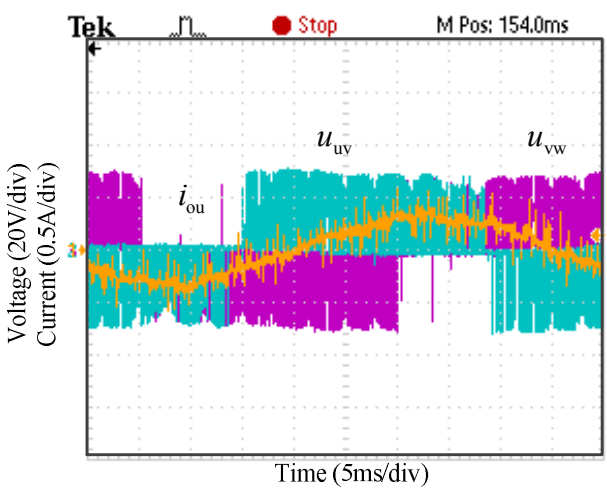

Fig. 26. Output line voltage of Phase U \& Phase V with phase U current.

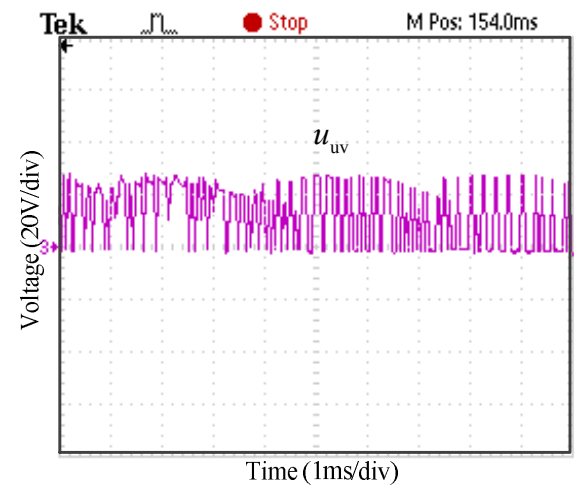

Fig. 27. Detailed output line voltage of Phase U. 


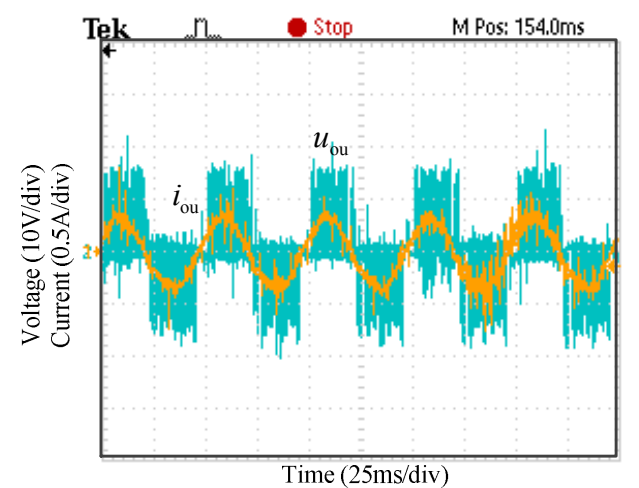

Fig. 28. Output phase voltage and phase current of Phase U.

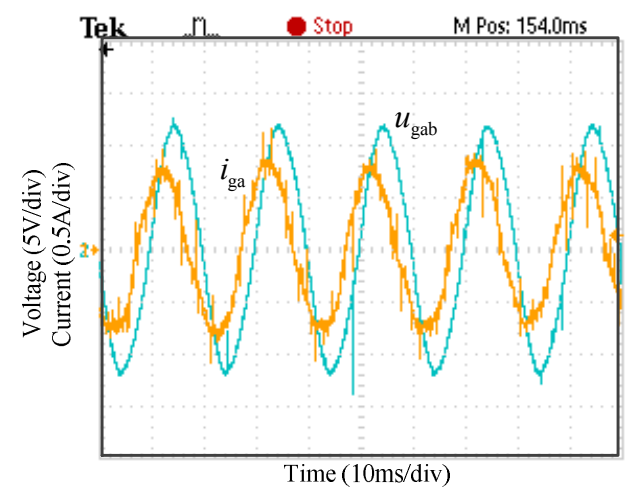

(a) Waveforms.
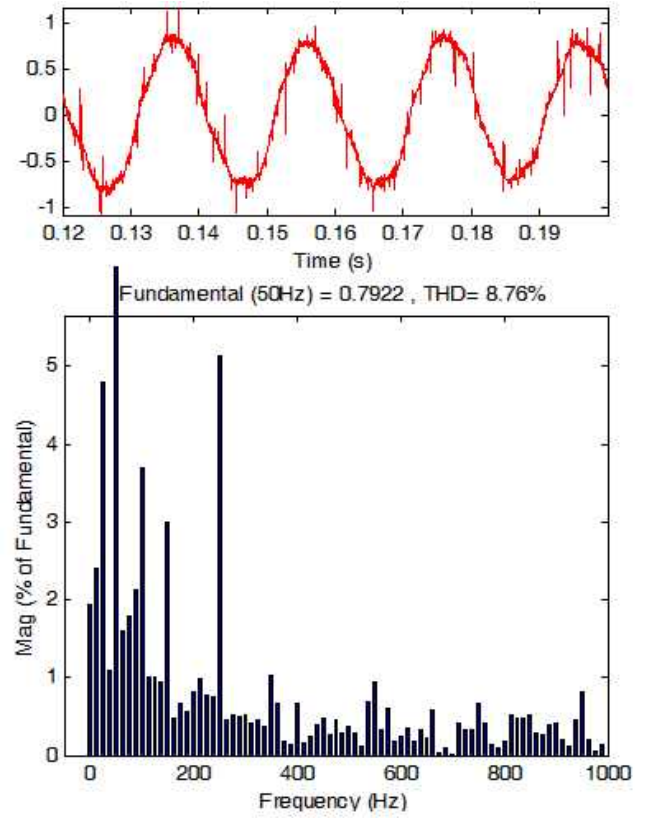

(b) FFT analysis of current.

Fig. 29. Matrix converter side grid line voltage and phase current in generation mode.

voltage and the secondary transformer voltage. The input voltage of the three phase matrix converter is good for further modulation.

Fig. 25 shows the DC bus voltage of the three phase TSMC.

Fig. 26 shows the output line voltage of Phase U and Phase
$\mathrm{V}$ as well as the Phase $\mathrm{U}$ current when the converter is connected to a resistance-inductance load with an output voltage of $20 \mathrm{~Hz}$.

Fig. 27 gives the detailed output line voltage of Phase $U$ with a resistance-inductance load.

Fig. 28 shows the output phase voltage and phase current of Phase $\mathrm{U}$ with a resistance-inductance load.

The Matrix converter side grid line voltage and the phase current when the converter is in generation mode are shown in Fig. 29. The two side of the converter are connected to a $50 \mathrm{~Hz}$ power grid. It is apparent that the grid current is sinusoidal with a THD equal to $8.76 \%$. Some $3^{\text {rd }}$ and $5^{\text {th }}$ order harmonics exist because the threshold value $U_{\mathrm{d}}$ (analyzed in Fig. 8) is set to be $5 \mathrm{~V}$ for safety reasons.

\section{CONCLUSIONS}

In this paper, a new medium-voltage matrix converter topology for wind power generation with medium-frequency transformer isolation has been introduced. It has been shown that a medium-voltage medium frequency transformer (MFT) can be realized with several series connected single phase multi-level AC-AC converters and three-phase matrix converters as an interface to a wind power generation system. Four topology configurations are put forward to fit different voltage levels and to reduce system weight and volume. A modulation and control strategy has been developed to manage the power flow of a wind power generation system. A novel single phase AC-AC converter topology and a reliable six-step switching technique are proposed to eliminate the switching losses and the use of clamping circuits. Furthermore, a novel symmetrical 11-segment modulation strategy for a TSMC is proposed to reduce the harmonics with the medium frequency chopping condition. Simulations validate the functionality of the topology and the control strategy. Experimental results have been obtained to verify the converter topology and the control strategy.

\section{REFERENCES}

[1] M. Chinchilla, S. Arnaltes, and J.C. Burgos, "Control of permanent-magnet generators applied to variable-speed wind-energy systems connected to the grid," IEEE Trans. Energy Conversion, Vol. 21, No. 1, pp. 130-135, Mar. 2006.

[2] W. Lixiang, T. A. Lipo and R. A. Lukaszewski, "Comparison of IGBT cycling capabilities for different AC/AC topologies," IEEE Trans. Ind. Appl., Vol. 46, No. 6, pp. 2475-2483, Nov. 2010.

[3] D. Casadei, G. Serra, A. Tani, and L. Zarri, "Matrix converter modulation strategies: a new general approach based on space-vector representation of the switch state," IEEE Trans. Ind. Electron., Vol. 49, No. 2, pp. 370-381, Apr. 2002.

[4] P. W. Wheeler, J. Rodriguez, J. C. Clare, L. Empringham, and A. Weinstein, "Matrix converters: a technology review," IEEE Trans. Ind. Electron., Vol. 49, No. 2, pp. 276-288, Apr. 2002.

[5] L. Helle, K.B. Larsen, A.H. Jorgensen, S. Munk-Nielsen, and F. Blaabjerg, "Evaluation of modulation schemes for 
three-phase to three-phase matrix converters," IEEE Trans. Ind. Electron., Vol. 51, No. 1, pp. 158-171, Feb. 2004.

[6] K. Jun, E. Yamamoto, M. Ikeda, and E. Watanabe, "Medium-voltage matrix converter design using cascaded single-phase power cell modules," IEEE Trans. Ind. Electron., Vol. 58, No. 11, pp. 5007-5013, Nov. 2011.

[7] K. Jun, N. Takada, E. Yamamoto, and E. Watanabe, "High power matrix converter for wind power generation applications," in Proc. ICPE \& ECCE, pp. 1331-1336, 2011.

[8] F. Haifeng and L. Hui, "A novel phase-shift bidirectional DC-DC converter with an extended high-efficiency range for $20 \mathrm{kVA}$ solid state transformer," in Proc. ECCE, pp. 3870-3876, 2010

[9] S.C. Kim, S.H. Jeong, S.H. Nam, "High power density, high frequency, and high voltage pulse transformer," KIEE International Transactions on Electrical Machinery and Energy Conversion Systems, Vol. 11B, No.4, pp. 180-184, Dec. 2001.

[10] L. Heinemann, "An actively cooled high power, high frequency transformer with high insulation capability", in Proc. APEC, pp. 352-357, 2002.

[11] L. Bisenieks, D. Vinnikov, and I. Galkin, "New isolated interface converter for grid-connected PMSG based wind turbines," in Proc. EEEIC, pp. 1-4, 2011.

[12] J. Darbyshire, and C.V. Nayar, Modelling, "Simulation and testing of grid connected small scale wind systems", in Proc. AUPEC, pp. 1-6. 2007.

[13] X. Li, and A.K.S. Bhat, "A utility-interfaced phase-modulated high-frequency isolated dual LCL DC/AC converter," IEEE Trans. Ind. Electron., Vol. 59, No. 2, pp. 1008-1019, Feb. 2012

[14] P. Drabek, Z. Peroutka, M. Pittermann, X. Ce, and M. Dl, "New configuration of traction converter with medium-frequency transformer using matrix converters," IEEE Trans. Ind. Electron., Vol. 58, No. 11, pp. 5041-5048, Nov. 2011.

[15] Z. Zheng, Z. Gao, C. Gu, L. Xu, K. Wang, and Y. Li, "Stability and voltage balance control of a modular converter With multiwinding high-frequency transformer," IEEE Trans. Power Electron., Vol. 29, No. 8, pp. 4183-4194, Aug. 2014.

[16] C. Gu, Z. Zheng, Y. Li, H. Ma, and Z. Gao, "Power balancing control of a multilevel converter using high-frequency multi-winding transformer," in Proc. IPEMC, pp. 1866-1870, 2012.

[17] H.S. Krishnamoorthy, D. Rana, and P.N. Enjeti, "A new wind turbine generator/battery energy storage utility interface converter topology with medium-frequency transformer," in Proc. APEC, pp. 2218-2224, 2013.

[18] C. Rodriguez, and G. Amaratunga, "Long-lifetime power inverter for photovoltaic AC modules," IEEE Trans. Ind. Electron., Vol. 55, No. 7, pp. 2593-2601, July 2008.

[19] J. Taufiq, "Power electronics technologies for railway vehicles," in Proc. PCC, pp. 1388-1393, 2007.

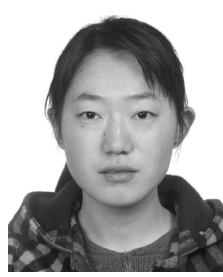

Chunyang Gu was born in Heilongjiang, China, in 1988. She received her B.S. degree in Electrical Engineering from the Department of Electrical Engineering, School of Electrical Engineering and Automation, Harbin Institute of Technology, Harbin, China, in 2010. She is currently working toward her $\mathrm{Ph} . \mathrm{D}$. degree in Electrical Engineering at Tsinghua University,
Beijing, China. Her current research interests include multilevel converters, power electronic transformers, and the control of power converters.

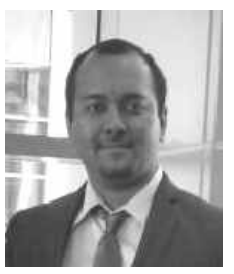

Harish S. Krishnamoorthy received his B.S. degree in Electrical and Electronics Engineering from the National Institute of Technology, Tiruchirappalli, India, in 2008. $\mathrm{He}$ is currently working toward his Ph.D. degree in Electrical Engineering at Texas A\&M University, College Station, TX, USA. From 2008 to 2010, he was an Engineer for General Electric (GE) Energy, India. His current research interests include high-power density converter designs, renewable energy conversions, etc. He holds a U.S. patent and has several international publications to his name.

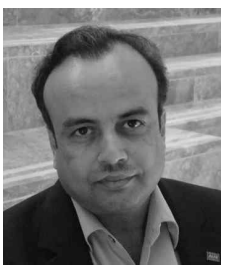

Prasad N. Enjeti received his B.S. degree from Osmania University, Hyderabad, India, in 1980, his M.S. degree from the Indian Institute of Technology, Kanpur, India, in 1982, and his Ph.D. degree from Concordia University, Montreal, QC, Canada, in 1988, all in Electrical Engineering. In 1988, he became an Assistant Professor in the Department of Electrical Engineering, Texas A\&M University, College Station, TX, USA. In 1994, he was promoted to an Associate Professor, and in 1998, he became a Full Professor. His current research interests include advance converters for power supplies and motor drives, power quality issues, active power filter development, converters for fuel cells, wind energy systems, power electronic hardware for flywheels, ultra-capacitor type energy storage/discharge devices for ride-through and utility interface issues.

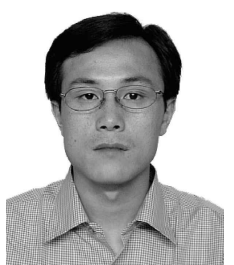

Zedong Zheng was born in Shandong, China, in 1980. He received his B.S. and Ph.D. degrees in Electrical Engineering from the Department of Electrical Engineering, Tsinghua University, Beijing, China, in 2003 and 2008, respectively. He is currently an Associate Professor in the Department of Electrical Engineering, Tsinghua University. His current research interests include power electronics converters and high-performance motor control systems.

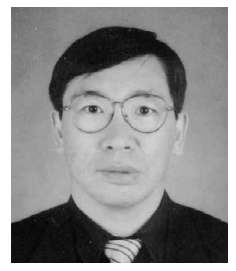

Yongdong Li was born in Hebei, China, in 1962. He received his B.S. degree from the Harbin Institute of Technology, Harbin, China, in 1982, and his M.S. and Ph.D. degrees from the Department of Electrical Engineering, Institut National Polytechnique de Toulouse, Toulouse, France, in 1984 and 1987, respectively. Since 1996, he has been a Professor with Department of Electrical Engineering, Tsinghua University, Beijing, China. He is also the lead developer of the Power Electronics and Motor Control (PEMC) Laboratory, Tsinghua University. He was an Invited Professor with the Institut National Polytechnique de Toulouse and the Dean of the School of Electrical Engineering, Xinjiang University, Urumchi, China. His current research interests include power electronics, machine control and wind power generation. 